\title{
FORMAÇÃO E EDUCAÇÃO DE JOVENS E ADULTOS NOS DIFERENTES ESPAÇOS DA VIDA
}

\begin{abstract}
APRESENTAÇÃO
A Educação de Jovens e Adultos-EJA tem vindo a reforçar a própria identidade, ao longo das últimas décadas, quer enquanto domínio epistemológico, quer enquanto campo de práticas, com especificidade ímpar. Se é verdade que todos temos consciência de que sem a capacidade de aprendizagem e de adaptação e transformação dos contextos de vida das populações jovens e adultas não teria sido possível a sobrevivência da espécie humana, a complexificação das formas de vida que a modernidade foi gerando, impuseram a necessidade de olhar para aquele longo passado e para uma história já consolidada, com um olhar reflexivo e crítico, capaz de nos permitir ir consolidando uma comunidade científica envolvida na necessária (re)construção de conhecimento que ajude a encontrar as melhores soluções para as contínuas e indispensáveis transformações que as pessoas necessitam empreender.

Os enunciados da obrigação de pensar práticas educativas diferenciadas para as distintas idades da vida atravessam diferentes formas de produção literária e filosófica, desde a Antiguidade Clássica até a literatura utópica do período do Renascimento, passando pelas primeiras obras do pensamento pedagógico moderno, tendo sempre como ideia comum nunca podermos construir melhores sociedades (mais justas, melhor administradas, mais fraternas, mais igualitárias e mais livres) sem que essas mudanças resultem da ação mais imediata das gerações jovens e adultas, porque apenas elas dispõem dos recursos necessários para esse empreendimento. Ora, como essas transformações necessitam suportar conhecimento e valores, assumindo uma intencionalidade orientada para determinados fins e mobilizando os meios necessários, começou a ser indispensável a procura de respostas que pudessem configurar uma área de trabalho científico, com vitalidade produtiva, de valor heurístico e compreensivo suficientes para promover o envolvimento de todas as pessoas na recriação de novas realidades, para si próprias e para os seus contextos de vida.

Estes contornos identitários começaram a ser desenhados a partir de um distanciamento progressivo em relação às modalidades tradicionais de educação, contra as estruturas mentais, ideológicas, culturais e metodológicas conservadoras, privilegiadoras da herança cultural, do conformismo, da ordem e da infantilização do ato educativo, que colocavam os jovens e adultos como objeto de educação. Como nos lembrou Paul Lengrand num dos livros preparatórios do movimento da Educação Permanente, esse desafio transformador de práticas educativas para jovens e adultos teve origem e desenvolveu-se fora dos caminhos da escola e da universidade, nos colégios populares da Dinamarca, nas organizações de ensino mútuo, nas instituições de educação operária, nas cooperativas e nos movimentos e associações de educação popular, reunindo participações incontornáveis e decisivas, com reconhecimento planetário, como é o caso de Paulo Freire, talvez um dos exemplos mais eloquentes de contributos capazes de associar a praxis e a construção de conhecimento, para a consolidação do entendimento das pessoas adultas como sujeitos da sua própria educação e agentes de transformação das suas existências.

Este conjunto interrelacionado de convicções contribuiu, igualmente, para sedimentar a consagração do direito de todas as pessoas, em todas as idades da vida, à educação, com as especificidades de fins e meios aconselhados por cada idade. Jack Mezirow, um dos últimos autores a teorizar uma proposta robusta e reconhecida para a educação de jovens e adultos, assinala a necessidade de observar essas diferenças, uma vez que a nossa vida se organiza em dois grandes períodos de desenvolvimento: o primeiro, coincidente com a infância e a adolescência, destina-se predominantemente a descodificar rotinas biológicas e a codificar
\end{abstract}


rotinas sociais, enquanto o segundo, nas fases da juventude e posteriores, podemos ser desafiados a questionar criticamente estes processos de socialização, muitas vezes construídos de maneira acrítica e pouco consciente. Por isso mesmo é que, a educação para as primeiras idades da vida deve ser predominantemente formativa, enquanto a destinada às idades do segundo período deve assumir uma dimensão transformativa.

Para que seja possível garantir o direito de todas as pessoas à educação, propiciando atividades educativas transformativas, condizentes com os avanços do conhecimento neste domínio, é preciso defender políticas públicas responsáveis e credíveis, integradas por profissionais com formação adequada e envolvida por uma pesquisa preocupada e atuante. Estas serão as condições para a educação e o desenvolvimento (social, cultural, político e econômico) se desafiarem mutuamente, tendo a transformação contínua da interação das pessoas e dos seus espaços de vida como preocupação dominante.

No ano em que celebramos o centenário do nascimento de Paulo Freire, um dos nomes maiores e mais reconhecidos, a nível mundial, neste domínio, a Nova Revista Amazônica, publica um dossiê testemunhando os esforços de pesquisadores, na tarefa de contribuir para dignificar a educação de jovens e adultos, com textos que se orientam, em particular, a reflexão sobre as práticas e a análise dos contextos.

Assim, os artigos integrantes do dossiê "Educação de Jovens e Adultos em diferentes espaços da vida" promoveram um diálogo entre países, Brasil e Portugal, estados brasileiros e se evidenciou a diversidade étnica, com ênfase aos povos quilombolas. A Amazônia se destacou em grande parte das investigações apresentadas e Paulo Freire foi figura presente em todas as pesquisas. Temas atuais como a Pandemia da Covid-19 e as Metodologias ativas também estão presentes na coletânea.

No artigo Formação profissional e desenvolvimento local: relações e oportunidades a partir da elaboração do projeto educativo de um município Português promoveu-se a discussão das políticas de formação profissional alinhadas às inovações tecnológicas por meio de um projeto estratégico para a educação em contexto municipal, projeto desenvolvido entre a Universidade de Coimbra e o município de Sintra, em Portugal.

No artigo A EJA em tempos de Pandemia de Covid -19: Reflexões sobre os direitos e políticas educacionais na Amazônia bragantina analisou-se as políticas educacionais em tempos de pandemia na Amazônia bragantina, com olhar voltado para a Educação de Jovens e Adultos. Evidenciou-se as políticas compensatórias de diminuições de tempos e conteúdos, fechamento de turmas, redução do número de matrículas, além do fechamento dos programas específicos para a EJA, agravando a situação pandêmica.

No artigo Aprendizagem Significativa como alicerce para Metodologias Ativas no ensino de Ciências: uma interlocução em prol da Educação de Jovens e Adultos, as reflexões sobre a EJA na busca de uma participação ativa do aluno, frisou a importância da formação docente em diálogo com os autores Freire, Ausubel, Moran e Chassot, os quais promoveram uma nova compreensão de estratégias eficazes à Aprendizagem Significativa em Ciências.

Paulo Freire é o ponto central do artigo A questão do tema gerador em Paulo Freire: práticas e experimentações em Tracuateua-PA, suas bases teóricas e práticas foram tomadas como referência nas escolas do município de Tracuateua-PA e suas ideias possibilitaram a resistência às pressões no cenário político atual brasileiro, mantendo o trabalho pedagógico alicerçado na escuta e dialogicidade. 
Por fim, o artigo Retratos da EJA na Amazônia Marajoara: desafios do ensino da Língua Inglesa na educação escolar Quilombola, discutiu o ensino da Língua Inglesa para alunos da Educação de Jovens e Adultos na perspectiva da Educação Escolar Quilombola, do município de Salvaterra. A pesquisa realçou as questões étnico-raciais nas aulas como sendo um campo desafiador no alcance da qualidade do ensino. A necessidade de formação continuada dos professores de Língua Inglesa pautada nas relações étnico-raciais é uma necessidade emergencial, pois os dados indicaram desafios associados especialmente às suas práticas pedagógicas.

Desejamos uma boa leitura deste rico e denso material, que ora vos apresentamos.

\section{Os organizadores}

\section{Dr. Luís Alcoforado}

Doutor em Ciências da Educação pela Universidade de Coimbra, Professor na Faculdade de Psicologia e de Ciências da Educação da Universidade de Coimbra e Investigador do Grupo de Políticas Educativas e Dinâmicas Educacionais (GRUPOEDE) do Centro de Estudos Interdisciplinares do Século XX (CEISXX). Foi Coordenador do Mestrado em Educação e Formação de Adultos e Intervenção Comunitária (2012 - 2018), é Coordenador do Mestrado em Ciências da Educação e Membro da Comissão de Coordenação do Doutoramento em Ciências da Educação, da Faculdade de Psicologia e de Ciências da Educação da Universidade de Coimbra. E-mail: lalcoforado@fpce.uc.pt.

\section{Dra. Nívia Maria Vieira Costa}

Doutora em Educação pela Universidade Federal do Ceará- UFC. Pós-doutora em Educação de Adultos pela Faculdade de Psicologia e de Ciências da Educação da Universidade de Coimbra. Professora do Instituto Federal de Educação, Ciência e Tecnologia do ParáIFPA/Campus Bragança. Pesquisadora da Cátedra Paulo Freire da Amazônia e Coordenou o Projeto de Pesquisa Interinstitucional "Paulo Freire: Diversidade e Educação", entre IFPA e UFPA. Avaliadora do INEP/MEC de Instituições e Cursos Superiores; Membro do grupo de pesquisa ETTHOS, do IFPA/ Campus Bragança e NUPEEFT, do IFG/ Campus Goiânia. Email: nivia.costa@ifpa.edu.br. 